\title{
A triplex quantitative real-time PCR assay for differential detection of human adenovirus serotypes 2, 3 and 7
}

Fang-zhou Qiu ${ }^{2,1+}$, Xin-xin Shen ${ }^{2 \dagger}$, Meng-chuan Zhao ${ }^{3 \dagger}$, Li Zhao ${ }^{2,1}$, Su-xia Duan ${ }^{2,3}$, Chen Chen ${ }^{2}$, Ju-Ju Qi ${ }^{2,1}$, Gui-xia Li ${ }^{3}$, Le Wang ${ }^{3}$, Zhi-shan Feng ${ }^{3^{*}}$ and Xue-jun $\mathrm{Ma}^{2^{*}}$

\begin{abstract}
Background: Human adenovirus (HAdV) serotypes 2, 3 and 7 are more prevalent than other serotypes and have been associated with severe pneumonia in pediatric children. Molecular typing of HAdV is not routinely performed in clinical diagnostic laboratories as it is time-consuming and labor-intensive.

Methods: In the present study, we developed a triplex quantitative real-time PCR assay (tq-PCR) in a single closed tube for differential detection and quantitative analysis of HAdV serotypes 2, 3 and 7. The sensitivity, specificity, reproducibility and clinical performance of tq-PCR were evaluated.

Results: The analytical sensitivity of the tq-PCR was 100 copies/reaction for each of HAdV serotypes 2, 3 and 7, and no cross-reaction with other common respiratory viruses or HAdV serotypes 1,4,5,6,31,55 and 57 was observed. The coefficients of variation (CV) of intra-assay and inter-assay were between $0.6 \%$ to $3.6 \%$. Of 138 previously-defined HAdV-positive nasopharyngeal aspirates samples tested, the detection agreement between tq-PCR and nested PCR was $96.38 \%(133 / 138)$.
\end{abstract}

Conclusion: The proposed tq-PCR assay is a sensitive, specific and reproducible method and has the potential for clinical use in the rapid and differential detection and quantitation of HAdV serotypes 2, 3 and 7.

Keywords: Pneumonia, HAdV, Triplex quantitative real-time PCR, Clinical

\section{Background}

Human adenoviruses (HAdV) are nonenveloped icosahedral double-stranded DNA virus which belongs to the Mastadenovirus genus and classified as 7 HAdV species (HAdV-A to -G) including more than 64 serotypes [1]. Clinical mild infections associated with HAdV includes fever, acute respiratory illness, gastroenteritis and conjunctivitis. Rare manifestations of HAdV infections are hemorrhagic cystitis, hepatitis, hemorrhagic colitis, pancreatitis, nephritis, meningoencephalitis and death [2]. Different HAdV serotypes have been associated with

\footnotetext{
*Correspondence: 15131129999@139.com; maxj@ivdc.chinacdc.cn ${ }^{\dagger}$ Equal contributors

${ }^{3}$ Children's Hospital of Hebei Province, Shijiazhuang 050031, Hebei, China ${ }^{2}$ Key Laboratory for Medical Virology, National Health and Family Planning Commission, National Institute for Viral Disease Control and Prevention, Chinese Center for Disease Control and Prevention, No. 155 Changbai Street, Chang ping District, Beijing 102206, China

Full list of author information is available at the end of the article
}

distinct clinical syndromes [3]. HAdV are one of the major pathogens associated with febrile respiratory illness in children [4]. And acute respiratory infections (ARI) are mainly caused by HAdV species B $(3,7,14,21,55)$, $\mathrm{C}(1,2,5,6)$ and $\mathrm{E}(4)$ worldwide [5]. Previous studies reported that HAdV 2, 3 and 7 were more prevalent and have been associated with severe pneumonia in China [3, 6-9].

HAdV pneumonia in pediatric patients can progress rapidly to multi-organ failure. Due to the lack of reliable and practical methods for HAdV typing by clinical laboratories, children with HAdV pneumonia may be misdiagnosed and inadequately treated. Although no antiviral drug has been approved to treat adenovirus pneumonia, accurate and prompt detection and typing of adenovirus is highly in demand to guide antiviral treatment, reduce the disease severity $[3,10]$ and

(c) The Author(s). 2018 Open Access This article is distributed under the terms of the Creative Commons Attribution 4.0 International License (http://creativecommons.org/licenses/by/4.0/), which permits unrestricted use, distribution, and 
contribute in the monitoring of outbreaks and dynamic assessment of viral loads in transplant patients [11].

The aim of this study is to develop a triplex quantitative real time PCR (tq-PCR) assay for rapid and differential detection of HAdV 2, 3 and 7 for potential clinical use, and investigate the prevalence of HAdV infection in Hebei province, China from June to November.

\section{Methods}

\section{Clinical samples}

Clinical samples used in this study were collected from 200 inpatients presenting with acute respiratory symptoms at the Children's Hospital of Hebei Province (China) between June and November, 2017. These specimens had been previously tested by the Respiratory Pathogen 13 Detection Kit [12] and 138 were found to be positive for HAdV and 62 were positive for some other respiratory virus. The clinical samples were nasopharyngeal aspirates and stored at $-80{ }^{\circ} \mathrm{C}$ until extraction of nucleic acid. And the study was conducted with the approval of the Ethics Committee of Children's hospital of Hebei Province, and written informed consents were obtained from the children's parents.

\section{Nucleic acid extraction}

Total $200 \mu \mathrm{L}$ of each clinical sample was treated with Master Pure Complete DNA and RNA purification kit (Epicenter Technologies, Madison, WI) according to the manufacturer's instructions. The extracts were eluted in $50 \mu \mathrm{L}$ of DNase- and RNase-free water and stored at $-80{ }^{\circ} \mathrm{C}$ until use.

\section{Primers and probes design}

Both complete and partial genomes of hexon gene were derived from GenBank databases. The sequences were aligned using Vector NTI. The forward primer of this study was derived from previously published [13] and the reverse primer, three MGB probes were newly designed from hexon gene sequences using oligo7. The primers were analyzed carefully to minimize primer- primer interactions, dimer formation among themselves and the formation of secondary structures in the multiplex PCR. The fluorescent reporter dyes for type 2, 3, 7 probes were FAM, HEX, and Cy5, respectively. The primer and probes sequences are outlined in Table 1.

\section{Preparation of DNA standards and standard curves}

PCR products of HAdV were obtained with the two step nested PCR as described in previous study [14]. The recombinant plasmids harboring the sequences of HAdV serotypes 2, 3 and 7 were constructed, respectively, and the insert size of each targeted sequence was 820 base pair (bp). Sequencing and cloning were done by TsingKe Biotech Corp (Beijing, China). The recombinant plasmids were used as standards for the quantitative analysis of tqPCR. The plasmids were serial 10 -fold diluted from $10^{8}$ to $10^{1}$ copy $/ \mu \mathrm{L}$ and stored $-20{ }^{\circ} \mathrm{C}$ until use. The tq-PCR standard curves were individually generated for HAdV serotypes 2, 3 and 7 by serial 10 -fold dilutions of the three recombinant plasmids with a known copy number from $10^{1}$ to $10^{8}$ copies $/ \mu \mathrm{L}$, and the dilutions were quantified by Nanodrop (NanoPhotometer N60, Germany).

\section{The $\mathrm{q}-\mathrm{PCR}$ and tq-PCR assays}

The mono q-PCR assay was performed in the CFX96TM real-time system (BIORAD, USA) using Premix Ex Taq (Probe qPCR), ROX plus (Takara, Dalian, China). PCR amplification was initially performed in $20 \mu \mathrm{L}$ reaction volume containing $10 \mu \mathrm{L}$ of reaction mixture (TaKaRa Ex Taq HS, dNTP Mixture, Mg2+, Tli RNaseH and ROX Reference Dye), $0.8 \mu \mathrm{L}$ of each of $20 \mu \mathrm{M}$ forward primer and reverse primer, $0.4 \mu \mathrm{L}$ of each of $10 \mu \mathrm{M}$ type 2,3 and 7 of HAdV probes, $2 \mu \mathrm{L}$ of total nucleic acid extracts, and $5.2 \mu \mathrm{L}$ of RNase-free water. The thermal cycling condition was as follows: one cycle of 20 s at $95{ }^{\circ} \mathrm{C}$; 40 cycles of $1 \mathrm{~s}$ at $95{ }^{\circ} \mathrm{C}, 20 \mathrm{~s}$ at $55^{\circ} \mathrm{C}$. Fluorescent signals were detected at the end of each cycle and the cycle threshold $(\mathrm{Ct})$ value $\leq 38$ was considered positive. The tq-PCR assay for the differential detection of HAdV serotypes 2,3 and 7 in one tube was performed in a

Table 1 The primer and probe of tq-pcr and nested pcr

\begin{tabular}{|c|c|c|c|c|c|}
\hline & Primer (Probe) & Sequence $\left(5^{\prime}-3^{\prime}\right)$ & GC content (\%) & $\operatorname{Tm}\left({ }^{\circ} \mathrm{C}\right)$ & Reference \\
\hline \multirow[t]{5}{*}{ tq-PCR } & F-primer & GGYCCYAGYTTYAARCCCTAYTC & $39.13 \%$ & $54.9^{\circ} \mathrm{C}$ & [13] This study \\
\hline & R-primer & AAYTTGAGGYTCTGGYTGATCKG & $39.13 \%$ & $55.7^{\circ} \mathrm{C}$ & \\
\hline & Probe2 & FAM-TGTGAGTGGGAACAAACCGAAG-MGB & $50.00 \%$ & $60.6^{\circ} \mathrm{C}$ & \\
\hline & Probe3 & HEX-ACAATGCAGTAACTACCACCACAA-MGB & $41.67 \%$ & $59.6^{\circ} \mathrm{C}$ & \\
\hline & Probe7 & Cy5-TTACTGCAGACAACAAGCCCAT-MGB & $45.45 \%$ & $59.7^{\circ} \mathrm{C}$ & \\
\hline \multirow[t]{4}{*}{ Nested PCR } & AdhexF1 & TICTITGAC ATICGIGGIGTICTIGA & $38.46 \%$ & $60.3^{\circ} \mathrm{C}$ & [13] \\
\hline & AdhexR1 & CTGTCIACIGCCTGRTTC CACA & $45.45 \%$ & $59.8^{\circ} \mathrm{C}$ & \\
\hline & AdhexF2 & GGYCCYAGYTTYAARCCCTAYTC & $39.13 \%$ & $54.9^{\circ} \mathrm{C}$ & \\
\hline & AdhexR2 & GGTTCTGTCICCCAGAGARTCIAGCA & $50.00 \%$ & $63.3^{\circ} \mathrm{C}$ & \\
\hline
\end{tabular}


volume of $20 \mu \mathrm{Lcontaining} 10 \mu \mathrm{L}$ of reaction mixture, 0 . $8 \mu \mathrm{L}$ of each of $20 \mu \mathrm{M}$ forward primer and reverse primer, $0.4 \mu \mathrm{L}$ of each of $10 \mu \mathrm{M}$ type 2,3 and 7 of HAdV probes, $1 \mu \mathrm{L}$ of each of plasmid mixture, and $4.2 \mu \mathrm{L}$ of RNase-free water. The thermal cycling condition was unchanged.

\section{Analytical sensitivity, specificity and reproducibility of tq-PCR assay}

The analytical sensitivity analysis of tq-PCR assay was carried out using 10-fold dilutions of plasmid range from $10^{1}$ to $10^{8}$ copies $/ \mu \mathrm{L}$ and the specificity was evaluated by using 62 other common respiratory viruses-positive samples retrospectively tested by Respiratory Pathogen 13 Detection Kit (13× kit) [15]. The intra-assay coefficients of variation of this assay was tested using three plasmids in three replicates and inter-assay reproducibility was tested in three different days within a week.

\section{Comparison of clinical performance between the tq-PCR assay and two step nested PCR assay}

A total of $138 \mathrm{HAdV}$-positive clinical samples from Children's hospital of Hebei Province (China) were detected with the tq-PCR assay. For comparison, two step nested PCR was performed in parallel on these samples. The nested PCR products of all the 138 samples were sequenced to confirm the results of tq-PCR assay.

\section{Results}

Sensitivity

The analytical sensitivity of the tq-PCR assay for each of human adenovirus 2, 3 and 7 was approximately $10^{2}$ copies/reaction (Fig. 1, Table 2). The standard curves of the tq-PCR assay were generated. As is shown Fig. 1d, the standard curves were linear in the range of $10^{8}-10^{2}$ copies for the HAdV serotypes 2, 3 and 7. The correlation coefficient $\left(\mathrm{R}^{2}\right)$ of HAdV serotypes 2,3 and 7 were $0.996,0.973,0.985$, respectively and amplification efficiencies for the different targets were 105.2\%, 106.6\% and $103.7 \%$, respectively. Then we took plasmids of HAdV serotypes 2, 3 and 7 into one tube to simulate coinfection, a analytical sensitivity of approximately $10^{3}$ copies/reaction of each of these three plasmids was obtained.

\section{Specificity}

A total of 62 samples positive for other common respiratory pathogens were used to test the tq-PCR assay specificity. These pathogens included rhinovirus, parainfluenza virus, human bocavirus, coronavirus, influenza $A$ and $B$ viruses, human metapneumovirus, Mycoplasma pneumonia and Chlamydophila. The tq-PCR assay showed no crossreactions with these pathogens (data not shown). Other HAdV species A (31), B (55), C (1,5,6), E (4) from enrolled
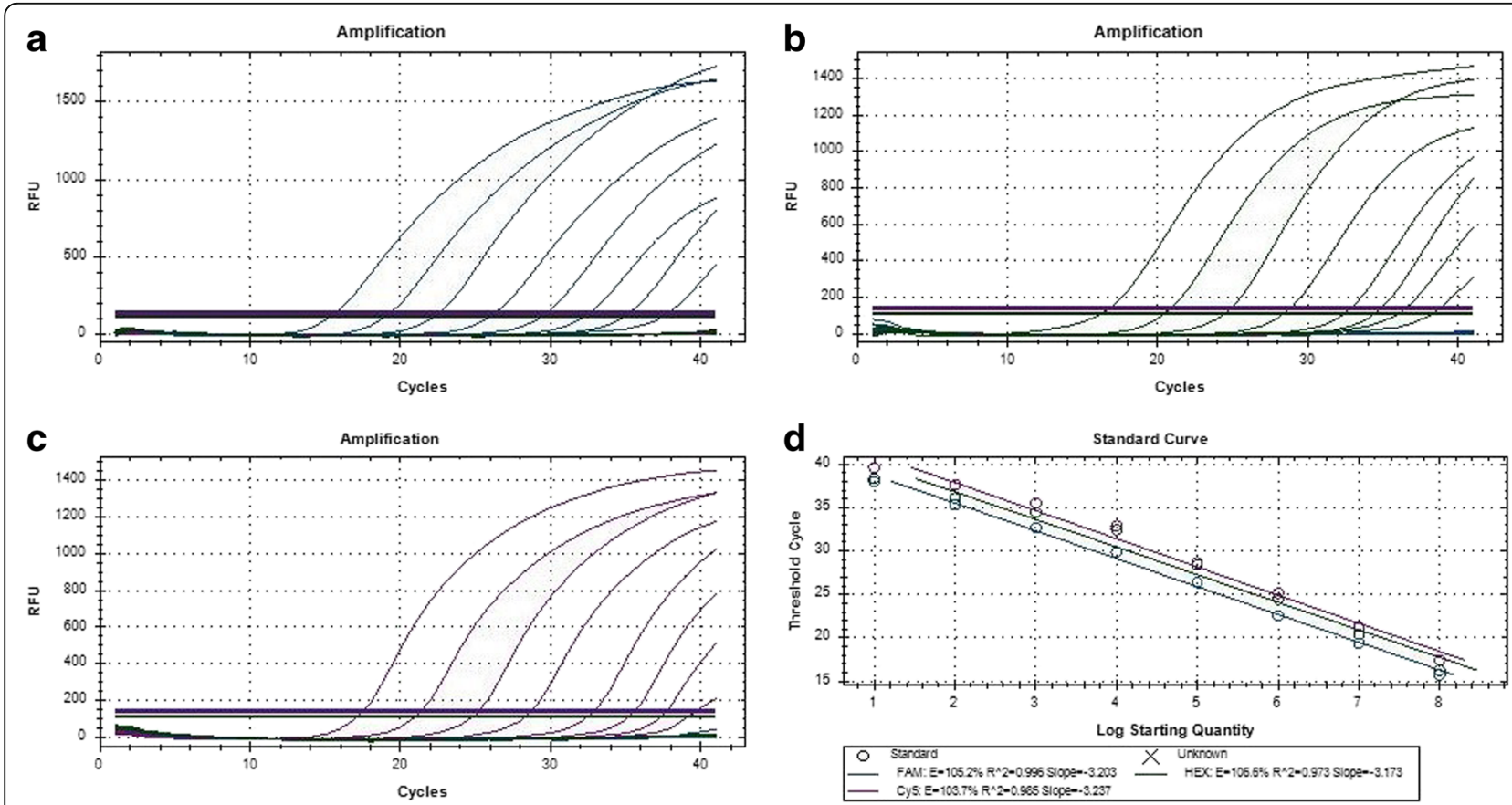

Fig. $1 \mathbf{a}, \mathbf{b}$, and $\mathbf{c}$ are amplification curves of the HAdV serotypes 2, 3 and 7, respectively using serial 10-fold dilutions of the three recombinant plasmids from $10^{8}$ to $10^{1} \mathrm{copy} / \mu \mathrm{l}$, and $\mathbf{d}$ is the standard curves of the tq-PCR using single template individually. The correlation coefficient $\left(\mathrm{R}^{2}\right)$ of HAdV serotypes 2,3 and 7 were $0.996,0.973,0.985$, respectively and amplification efficiencies for the different targets were $105.2 \%, 106.6 \%$ and $103.7 \%$, respectively 
Table 2 detection limit of tq-PCR

\begin{tabular}{llll}
\hline Copies/reaction & Ad2 & Ad3 & Ad7 \\
\hline $10^{1}$ copy $/ \mu \mathrm{L}$ & $17 / 20$ & $5 / 20$ & $3 / 20$ \\
$10^{2}$ copy $/ \mu \mathrm{L}$ & $20 / 20$ & $20 / 20$ & $20 / 20$ \\
$10^{3}$ copy $/ \mu \mathrm{L}$ & $20 / 20$ & $20 / 20$ & $20 / 20$ \\
\hline
\end{tabular}

HAdV-positive samples were also tested, and no positive results were obtained.

\section{Reproducibility}

In order to determine the intra-assay variability of the standard plasmids, three 100-fold dilutions from $10^{7}$ $10^{3}$ copies/ $\mu \mathrm{L}$ of HAdV serotypes 2,3 and 7 plasmids were detected three times within the same run, the coefficient of variation (CV) that was obtained ranged from0.6 to 3.6 for all the plasmids (Table 3). The interassay variability was evaluated by testing three dilutions of plasmids $\left(10^{7}-10^{3}\right.$ copies $\left./ \mu \mathrm{L}\right)$ on three different days with a week and gave a CV ranging from 1.0 to 3.6 for all the viral concentrations detected (Table 4).

\section{Agreement between the tq-PCR and two step nested PCR} Totally, 138 clinical samples previously confirmed adenovirus-positive were detected by tq-PCR assay. The results indicated that $42(30.43 \%)$ were serotype 2,40 (28.99\%) were serotype 3 and 5 (3.62\%) were serotype 7. Besides, two clinical samples were serotype 2,7 and 2,3 co-infections. HAdV serotypes 1 (22,15.94\%), 5 (13,9.42\%), 6 (6,4.35\%), 4 (2,1.45\%), 31(1,0.73\%), 55 $(1,0.73 \%)$ and $57(1,0.73 \%)$ were identified in 46 out of 138 samples by the sequencing of nested PCR product. The agreement between the tq-PCR and two step nested PCR was $96.38 \%(133 / 138)$ as showed in Table 5 . In the present study with limited sample size, the tq-PCR diagnostic sensitivities of HAdV2, 3, and 7 were found to be $97.7 \%$ (42/43), 90.1\% (40/44) and $100 \%(5 / 5)$, respectively.

\section{Discussion}

HAdV2, 3, and 7 were most commonly reported associated with ARI worldwide [3, 16]. Type2 is a common causes of ARI worldwide, but appear to be less virulent than type3 and type $7[17,18]$, Type 3 is the common

Table 3 Intra-assay of coefficient of variation (CV) of the tq-PCR

\begin{tabular}{|c|c|c|c|c|c|c|c|c|c|}
\hline & \multicolumn{3}{|c|}{$10^{7}$ copy/Ml } & \multicolumn{3}{|c|}{ 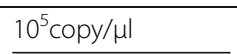 } & \multicolumn{3}{|c|}{$10^{3} \mathrm{copy} / \mu \mathrm{l}$} \\
\hline & $\mathrm{Ad} 2$ & $\mathrm{Ad} 3$ & Ad7 & $\mathrm{Ad} 2$ & Ad3 & Ad7 & $\mathrm{Ad} 2$ & Ad3 & Ad7 \\
\hline \multirow[t]{3}{*}{$C T$ value } & 17.74 & 20.12 & 20.43 & 24.95 & 26.39 & 26.39 & 32.15 & 33.11 & 35.23 \\
\hline & 17.40 & 19.05 & 20.88 & 24.24 & 26.44 & 27.05 & 33.08 & 33.96 & 34.85 \\
\hline & 18.34 & 19.56 & 20.29 & 26.05 & 26.13 & 27.31 & 32.59 & 34.52 & 34.5 \\
\hline Mean & 17.83 & 19.58 & 20.53 & 25.08 & 26.32 & 26.92 & 32.61 & 33.86 & 34.87 \\
\hline CV\% & $2.7 \%$ & $2.7 \%$ & $1.5 \%$ & $3.6 \%$ & $0.6 \%$ & $1.8 \%$ & $1.4 \%$ & $2.1 \%$ & $1.0 \%$ \\
\hline
\end{tabular}

Table 4 Inter assay of coefficient of variation (CV) of the tq-PCR

\begin{tabular}{|c|c|c|c|c|c|c|c|c|c|}
\hline & \multicolumn{3}{|c|}{ 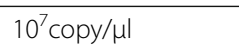 } & \multicolumn{3}{|c|}{ 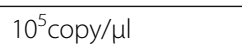 } & \multicolumn{3}{|c|}{$10^{3} \mathrm{copy} / \mu \mathrm{l}$} \\
\hline & $\mathrm{Ad} 2$ & Ad3 & Ad7 & $\mathrm{Ad} 2$ & $\mathrm{Ad} 3$ & Ad7 & $\mathrm{Ad} 2$ & Ad3 & $\mathrm{Ad} 7$ \\
\hline \multirow[t]{3}{*}{ CT value } & 17.52 & 20.56 & 21.23 & 25.59 & 26.33 & 27.23 & 32.78 & 33.45 & 35.12 \\
\hline & 18.20 & 21.05 & 20.42 & 25.24 & 27.48 & 27.14 & 33.15 & 34.15 & 34.01 \\
\hline & 18.83 & 19.97 & 20.79 & 26.75 & 26.71 & 27.88 & 32.47 & 34.41 & 34.3 \\
\hline Mean & 18.18 & 20.53 & 20.81 & 25.86 & 26.84 & 27.42 & 32.80 & 34.00 & 34.49 \\
\hline CV\% & $3.6 \%$ & $2.6 \%$ & $2.0 \%$ & $3.1 \%$ & $2.2 \%$ & $1.5 \%$ & $1.0 \%$ & $1.5 \%$ & $1.7 \%$ \\
\hline
\end{tabular}

serotype implicated in HAdV infections in children and adults $[6,16]$. Type 7 was the leading common serotype reported association with respiratory illness and it appears to be more virulent than other serotypes that may occur fatal pneumonias in immunocompetent children [7, 19] and adults [15]. In China, HAdV serotypes 2, 3 and 7 were the most prevalent types in pneumonia children [14]. Epidemic outbreaks caused by HAdV2, 3, and 7 affected numerous of populations in Chongqing, Guangzhou [20], Beijing [21], Shanxi [7], Hangzhou $[22,23]$ and Taiwan $[3,6,24]$. Thus differential detection of HAdV2, 3, and 7 from other serotypes in China should be of great significance in clinical setting. Besides, Species B HAdV types 3 and 7 have a high probability of disease association. In contrast, species C HAdV type 2 is often present as a bystander, as shown in multiple studies that included asymptomatic controls. Whereas types 3 and 7 have epidemic potential, being associated with outbreak clusters of ARI, type 2 and other species $C$ viruses rarely cause outbreaks.

In recent years, traditional PCR method to detect serotypes of adenovirus [25, 26] needs gel electrophoresis and sequencing, which significantly increases the risk of cross-contamination and is also time consuming and labor intensive. Fluorescence quantitative PCR for adenovirus typing showed acceptable sensitivity, specificity, and reproducibility. In previous studies by others $[9,27,28]$, the quantitative real-time PCR (panel assay) has proven to be of great value for the differential detection of HAdV types, but it is excessively reagentconsuming and costly. The nested PCR described above [13] seems more sensitive compared with other

Table 5 Agreement between the tq-PCR and two step nested PCR

\begin{tabular}{llllllll}
\hline & \multicolumn{2}{l}{ Triplex real-time PCR } & & \multicolumn{2}{l}{ Two step nest PCR } & Agreement \\
\cline { 2 - 3 } & Positive & Negative & & Positive & Negative & \\
\hline Ad2 & 42 & 94 & & 43 & 93 & $99.26 \%$ \\
Ad3 & 40 & 96 & & 44 & 92 & $97.05 \%$ \\
Ad7 & 5 & 131 & & 5 & 131 & $100 \%$
\end{tabular}

Footnote: of $138 \mathrm{HAdV}$ positive samples were detected by these two methods, as nested PCR can't show co-infection serotype 2, 7 and 2, 3, so only 136 clinical samples enrolled in agreement between the tq-PCR and two step nested PCR 
methods, but it's too inconvenient to be applicable in clinical laboratories with two-step amplification followed by sequencing. The tq-PCR assay in this study is more convenient and rapid to detect the most common HAdV serotypes 2, 3 and 7 in a single closed tube, thus it is very suitable for HAdV typing to meet clinical diagnosis purpose with advantage of low cost and less time. To our best knowledge, this is the first report on a tq-PCR assay for differential detection of HAdV serotypes 2, 3 and 7.

The tq-PCR revealed stable repeatability and a sensitivity of 100 copies/reaction and no cross reaction with other common respiratory viruses or HAdV serotypes $1,4,5,6,31$ and 55 . Five samples out of 138 negative by tq-PCR were positive by nested PCR, we speculated that these samples had a low virus titer that is below the detection limit of the tq-PCR. Although tq-PCR is slightly less sensitive compared with previous panel assay and nested PCR, and the efficiency of tq-PCR has not been demonstrated with quantitative results in clinical samples, it had sufficient sensitivity and adequate for the differential diagnosis of HAdV infections. Treatment options for patients with HAdV infection are limited [29]. Generally, when patients suffer from HAdV infection and show a rapid and high increase of viral load in the serum [10, 11], clinical protocols recommended are intensive supportive care and application of antiviral drugs [30], so early specific and differential diagnosis by the use of tq-PCR can be more targeted to ensure prompt treatment, which will be aided in effectively controlling the rapid replication of the HAdV in the body.

The HAdV spectrum associated with ARI is broad in China. In previous studies, HAdV types 1,4,5,6,14,55 $[24,31,32]$ were also reported to be associated with ARI. However, HAdV serotypes 2, 3 and 7 were more frequently reported to cause outbreaks and ARI. In our study, HAdV serotypes 2,3 and 7 were most prevalent $(63.4 \%, 83 / 138)$ in Hebei, China between June and November 2017, which is consistent with previous reports in China.

\section{Conclusions}

In conclusion, we established a tq-PCR assay with appropriate sensitivity, high specificity and reproducibility. tq-PCR assay offers the advantages of rapid detection, cost-effectiveness, and convenience and allows simultaneous and differential detection of HAdV serotypes 2, 3, and 7 , which might be of great potential for clinical use.

\section{Abbreviations}

ARI: Acute respiratory infections; CV: Coefficient of variation; HAdV: human adenovirus; PCR: Polymerase Chain Reaction; tq-PCR: Triplex quantitative realtime PCR assay

\section{Acknowledgments}

We acknowledge the children's hospital of Hebei Province, China for providing clinical specimen.

\section{Funding}

This work was supported by grants from the National key research and development plan of China (2016YFC1202700,2016YFC1200903 and 2017YFC1200503) and China Mega-Project for Infectious Disease (2017ZX10302301-004 and 2017ZX10104001).

\section{Availability of data and materials}

The datasets used and/or analyzed during the current study available from the corresponding author on reasonable request.

\section{Authors' contributions}

XJM and ZSF conceived the study. MCZ, GXL and LW conducted the clinical work. FZQXXS LZ SXD CC and JJQ performed the experiments. FZQ wrote this article, XJM revised it. All the authors have read and approved the final version of this manuscript.

\section{Ethics approval and consent to participate}

All aspects of the study were performed in accordance with national ethics regulations and approved by the Institutional Review Boards of National Institute for Viral Disease Control and Prevention, Center for Disease Control and Prevention of China and the Ethics Committee of Children's hospital of Hebei Province, china.

\section{Competing interests}

The authors declare that they have no competing interests.

\section{Publisher's note}

Springer Nature remains neutral with regard to jurisdictional claims in published maps and institutional affiliations.

\section{Author details}

'Hebei Medical University, Shijiazhuang 050031, Hebei, China. ${ }^{2}$ Key Laboratory for Medical Virology, National Health and Family Planning Commission, National Institute for Viral Disease Control and Prevention, Chinese Center for Disease Control and Prevention, No. 155 Changbai Street, Chang ping District, Beijing 102206, China. ${ }^{3}$ Children's Hospital of Hebei Province, Shijiazhuang 050031, Hebei, China.

Received: 1 February 2018 Accepted: 11 April 2018

Published online: 02 May 2018

\section{Reference}

1. Seto D, Chodosh J, Brister JR, Jones MS. Using the whole-genome sequence to characterize and name human adenoviruses. J Virol. 2011;85:5701-2.

2. Lynch JP 3rd, Kajon AE. Adenovirus: epidemiology, global spread of novel serotypes, and advances in treatment and prevention. Semin Respir Crit Care Med. 2016;37:586-91.

3. Lin MR, Yang SL, Gong YN, Kuo CC, Chiu CH, Chen CJ, Hsieh YC, Kuo CY, Fang CW, Tsao KC. Clinical and molecular features of adenovirus type 2, 3, and 7 infections in children in an outbreak in Taiwan, 2011. Clin Microbiol Infect. 2017:23:110-6.

4. Mulholland K. Global burden of acute respiratory infections in children: implications for interventions. Pediatr Pulmonol. 2003;36:469-74.

5. Demian PN, Horton KC, Adriana K, Rania S, Nageib HAM, Amany ES, Claire C, Gaynor AM. Molecular identification of adenoviruses associated with respiratory infection in Egypt from 2003 to 2010. BMC Infect Dis. 2014;14:50.

6. SY C, CN L, PH L, HH H, LY C WK, SF C, PI L, LM H, CL K. A communityderived outbreak of adenovirus type 3 in children in Taiwan between 2004 and 2005. J Med Virol. 2008:80:102-12.

7. Tang L, Li W, Tan X, Xu W. Adenovirus serotype 7 associated with a severe lower respiratory tract disease outbreak in infants in Shaanxi Province, China. Virol J. 2011;8:23.

8. Wo Y, Lu QB, Huang DD, Li XK, Guo CT, Wang HY, Zhang XA, Liu W, Cao WC. Epidemical features of HAdV-3 and HAdV-7 in pediatric pneumonia in Chongqing, China. Arch Virol. 2015;160:633-8.

9. Metzgar D, Gibbins C, Hudson NR, Jones MS. Evaluation of multiplex typespecific real-time PCR assays using the LightCycler and joint biological 
agent identification and diagnostic system platforms for detection and quantitation of adult human respiratory adenoviruses. J Clin Microbiol. 2010; 48:1397-403.

10. Lion T, Baumgartinger R, Watzinger F, Matthes-Martin S, Suda M, Preuner S, Futterknecht B, Lawitschka A, Peters C, Potschger U. Molecular monitoring of adenovirus in peripheral blood after allogeneic bone marrow transplantation permits early diagnosis of disseminated disease. Blood. 2003; 102:1114-9.

11. Schilham MW, Heemskerk B. High levels of adenovirus DNA in serum correlate with fatal outcome of adenovirus infection in children after allogeneic stem-cell transplantation. Clin Infect Dis. 2002;35:526-32.

12. Zhao MC, Li GX, Zhang D, Zhou HY, Wang H, Yang S, Wang L, Feng ZS, Ma $\mathrm{XJ}$. Clinical evaluation of a new single-tube multiplex reverse transcription PCR assay for simultaneous detection of 11 respiratory viruses, mycoplasma pneumoniae and chlamydia in hospitalized children with acute respiratory infections. Diagn Microbiol Infect Dis. 2017;88:115-9.

13. Lu X, Erdman DD. Molecular typing of human adenoviruses by PCR and sequencing of a partial region of the hexon gene. Arch Virol. 2006;151:1587-602.

14. Chen SP, Huang YC, Chiu CH. Clinical features of radiologically confirmed pneumonia due to adenovirus in children. J Clin Virol. 2013;56:7-12.

15. Cui X, Wen L, Wu Z, Liu N, Yang C, Liu W, Ba Z, Wang J, Yi S, Li H. Human adenovirus type 7 infection associated with severe and fatal acute lower respiratory illness and nosocomial transmission. J Clin Microbiol. 2015;53:746-9.

16. Gray GC, Mccarthy T, Lebeck MG, Schnurr DP, Russell KL, Kajon AE, Landry ML, Leland DS, Storch GA, Ginocchio CC. Genotype prevalence and risk factors for severe clinical adenovirus infection, United States 2004-2006. Clin Infect Dis. 2007:45:1120.

17. Lin KH, Lin YC, Chen HL, Ke GM, Chiang CJ, Hwang KP, Chu PY, Lin JH, Liu DP, Chen HY. A two decade survey of respiratory adenovirus in Taiwan: the reemergence of adenovirus types 7 and 4. J Med Virol. 2004;73:274.

18. Kajon AE, Mistchenko AS, Videla C, Hortal M, Wadell G, Avendaño LF. Molecular epidemiology of adenovirus acute lower respiratory infections of children in the south cone of South America (1991-1994). J Med Virol. 1996; 48:151-6.

19. Yamamoto D, Okamoto M, Lupisan S, Suzuki A, Saito M, Tamaki R, Mercado E, Sombrero L, Olveda R. Impact of human adenovirus serotype 7 in hospitalized children with severe fatal pneumonia in the Philippines. Jpn J Infect Dis. 2014:67:105-10.

20. Zhao S, Wan C, Ke C, Seto J, Dehghan S, Zou L, Zhou J, Cheng Z, Jing S, Zeng Z. Re-emergent human adenovirus genome type $7 \mathrm{~d}$ caused an acute respiratory disease outbreak in southern China after a twenty-one year absence. Sci Rep. 2014;4:7365.

21. Qiu S, Li P, Liu H, Wang Y, Liu N, Li C, Li S, Li M, Jiang Z, Sun H. Wholegenome sequencing for tracing the transmission link between two ARD outbreaks caused by a novel HAdV serotype 7 variant, China. Sci Rep. 2015; 5:13617.

22. Cheng J, Qi X, Chen D, Xu X, Wang G, Dai Y, Cui D, Chen Q, Fan P, Ni L. Epidemiology and transmission characteristics of human adenovirus type 7 caused acute respiratory disease outbreak in military trainees in East China. Am J Transl Res. 2016:8:2331-42.

23. Xie L, Yu XF, Sun Z, Yang XH, Huang RJ, Wang J, Yu A, Zheng L, Yu MC, Hu $X W$. Two adenovirus serotype 3 outbreaks associated with febrile respiratory disease and pharyngoconjunctival fever in children under 15 years of age in Hangzhou, China, during 2011. J Clin Microbiol. 2012;50:1879.

24. Lin YC, Lu PL, Lin KH, Chu PY, Wang CF, Lin JH, Liu HF. Molecular epidemiology and phylogenetic analysis of human adenovirus caused an outbreak in Taiwan during 2011. PLoS One. 2015;10:e0127377.

25. Biere B, Schweiger B. Human adenoviruses in respiratory infections: sequencing of the hexon hypervariable region reveals high sequence variability. J Clin Virol. 2010;47:366-71.

26. Xu WH, Mcdonough MC, Erdman DD. Species-specific identification of human adenoviruses by a multiplex PCR assay. J Clin Microbiol. 2000;38:4114-20.

27. Heim A, Ebnet C, Harste G, Pring-Akerblom P. Rapid and quantitative detection of human adenovirus DNA by real-time PCR. J Med Virol. 2003;70:228-39.

28. Lu X, Trujillolopez E, Lott L, Erdman DD. Quantitative real-time PCR assay panel for detection and type-specific identification of epidemic respiratory human adenoviruses. J Clin Microbiol. 2013;51:1089.

29. Schaar K, Geisler A, Kraus M, Pinkert S, Pryshliak M, Spencer JF, Tollefson AE, Ying B, Kurreck J, Wold WS. Anti-adenoviral artificial MicroRNAs expressed from AAV9 vectors inhibit human adenovirus infection in immunosuppressed Syrian hamsters. Mol Ther Nucleic Acids. 2017;8:300.
30. Schaar K, Röger C, Pozzuto T, Kurreck J, Pinkert S, Fechner H. Biological antivirals for treatment of adenovirus infections. Antivir Ther. 2016;21:559.

31. Lu QB, Tong YG, Wo Y, Wang HY, Liu EM, Gray GC, Liu W, Cao WC. Epidemiology of human adenovirus and molecular characterization of human adenovirus 55 in China, 2009\&ndash;2012. Influenzals\&lsother RespirViruses. 2014;8:302.

32. Huang G, Yu D, Zhu Z, Zhao H, Wang P, Gray GC, Meng L, Xu W. Outbreak of febrile respiratory illness associated with human adenovirus type 14p1 in Gansu Province, China. Influenza Other Respir Viruses. 2013;7:1048-54.

\section{Ready to submit your research? Choose BMC and benefit from:}

- fast, convenient online submission

- thorough peer review by experienced researchers in your field

- rapid publication on acceptance

- support for research data, including large and complex data types

- gold Open Access which fosters wider collaboration and increased citations

- maximum visibility for your research: over $100 \mathrm{M}$ website views per year

At BMC, research is always in progress.

Learn more biomedcentral.com/submissions 